\title{
The Consumption of Ergogenic Supplements in Physical Fitness Training (Survey of Members of the Fitness Centers in Sleman District)
}

\author{
Hernita Intan Gusmaya; Sugiyanto; Noer Rachma \\ Department of Sport Science, Postgraduate Program, Sebelas Maret University, Surakarta, Indonesia
}

http://dx.doi.org/10.18415/ijmmu.v6i2.689

\begin{abstract}
This research was motivated by curiosity of the researchers about supplements those were often consumed by sportsmen, especially on members of the fitness center so that this study discussed the consumption of ergogenic supplements in physical fitness training (survey of members of the fitness center in Sleman district). The purpose was to obtain an empirical picture of the phenomenon of consumption of ergogenic supplements, understanding of ergogenic supplements, the reality of consuming ergogenic supplements, and the impact of consumption of ergogenic supplements on members of the fitness center in Sleman Regency.

The research subjects used in this study were members of the fitness center in Sleman Regency which numbered 258 people. The method of data collection was through surveys conducted at 12 fitness centers located in Sleman district and research instruments using questionnaires. The data analysis technique used is descriptive statistics and chi-square test with $\mathrm{p}<0.05$ to assess the relationship between the variables chosen.

The results showed that as many as $34.1 \%$ of members consumed ergogenic supplements, $52.3 \%$ of members were highly knowledgeable about ergogenic supplements, $27.9 \%$ of members consumed only 1-2 kinds of ergogenic supplements, and $33.7 \%$ of members felt changes after taking ergogenic supplements. Besides that, it was found several variables related to the consumption of ergogenic supplements, namely age with P-value 0.005 , gender with P-value 0.000 and education with P-value 0.029 .
\end{abstract}

Keywords: Supplements; Ergogenic; Physical Fitness

\section{Introduction}

Sleman district is a district in the Special Region of Yogyakarta, Indonesia with an estimated population of about 1 million. Sleman Regency is one of the cities in Indonesia that has the potential to experience rapid development in various fields. This is inseparable from the flow of urbanization and modernization which has gradually influenced the lifestyle of the people in Sleman Regency. As a dynamic city, Sleman regency is a city with a high level of consumption. The consumption of nutritional supplements is a major dietary component that might have affected people in Sleman district. 
A high prevalence of supplement use was seen not only in developed countries but also in developing countries. Different prevalence rates of supplements use (including ergogenic aids) have been reported by physically active people ranging from $36.8 \%$ to as high as $88.6 \%$ (Atlee et.al., 2017; Braun et.al., 2009; Froiland et.al., 2004; Goston and Correia, 2010; Mc Dowall and Jill, 2007; Saeedi, 2012; Wiens et.al., 2014). Some surveys have indicated that approximately $50 \%$ of the general population, $76 \%$ of college athletes, and 100\% of bodybuilders take supplements (Mc Kinley Health Center, 2011).

There is no clear definition for supplements and different definitions are available (Maughan, Depiesse, Geyer, \& International Association of Athletics Federations, 2007). A Supplement is a product taken by mouth that contains a "dietary ingredient" used to supplement the diet. This can include vitamins, minerals, herbals, amino acid, and other substances (M.S. Howard et al. Journal of the American Pharmacists Association, 2018). Supplements, in general, are advertised and commercialized as having several purposes, mainly they are marketed such as to improve performance, increase muscle mass, decrease body fat, help control or lose weight, prevent illness and disease, treat medical problems, boost immunity, increase alertness or mental activity, and reduce stress (Goston and Correia, 2009). In addition to the benefits offered, supplements can also function as ergogenic aids.

According to Dr. Pat Harris, speaking at the Conference on Equine Sports Medicine and Science, the word "ergogenic" comes from Greek roots: ergon mean work, and genic means producing. Ergogenic substances would help the body produce more work. The "ergogenic" nutritional supplements are substances that supposedly improve the body's work capacity and athletic performance (Delimaris, 2017).

The availability and use of ergogenic substances have already common in sports and greatly increased in the past decade. Most are classified as supplements, which means the contents of the product and claims on the label have not been evaluated by the US Food and Drug Administration and may not have a scientific basis. New products appear on the market every week (McKinley Health Center, 2011).

Ergogenic supplements come in a variety of forms, including tablets, capsules, liquids, powders, and bars. Many of these products contain numerous ingredients in varied combinations and amounts. Among the more common ingredients are amino acids, protein, creatine, and caffeine (Office of Dietary Supplements of the National Institutes of Health, 2017). Statistics show that 50\% of unsportsmanlike people, $75 \%$ of young athletes and elite athletes all use different ergogenic substances as a source of health and comfort after exercise or as a way of recovering in training (Apostu, 2013).

In the United States, more than 3 million people were reported to be using or to have used ergogenic supplements (Palmer ME, Haller C, McKinney PE, et.al., 2003). Athletes have been the greatest consumers of many of these products (Burke L. et.al., 2006; Erdman KA., Fung TS., Reimer RA., 2006; Huang SS., Johnson K., Pipe AL., 2006) and their habits may be followed by other groups of individuals (Sobal J, Marquart LF., 1994; Striegel et.al., 2006), mainly those who exercise in gyms regularly (Morrison et.al, 2004). They consume the ergogenic supplement to get quick result from the training/exercise. They also become a major target for the supplement market due to their increased widespread existence and to the ease of their access to a variety of sports foods and nutritional supplements (El Khoury D, Antoine-Jonville S, 2012).

Basically, an individual does not need to consume supplements if their nutrition needs have already sufficient by food. Supplements are recommended for people who need and in certain situations/conditions. The American Dietetic Association, the Dietitians of Canada, and the American College of Sports Medicine stated that only those persons who restrict their energy intake, use severe weight-loss practices, eliminate one or more food groups from their diets or consume high-carbohydrate diets with low micronutrient density may require dietary supplementation (Huang SH, Johnson K, Pipe AL, 2006).

However, little is known about ergogenic supplement consumption among people exercising in fitness centers. Thus, this study aimed to assess ergogenic supplements consumption among fitness center members in Sleman District, Yogyakarta Province, Indonesia. 


\section{Methods}

This was a cross-sectional study carried out in 12 gyms in Sleman District, Yogyakarta Province, Indonesia. All the commercial gyms in this research were identified based on the internet listings. The data were collected over a period of 2 month (June-July).

A total of 258 fitness center participants were recruited to participate in this study. Disproportionate random sampling technique was used to determine the participants. Men and women were recruited and participants was categorized in 3 age-group (teenagers $<21 \mathrm{y}$, adults $21-40 \mathrm{y}$, elders $>40$ y). The participants had to be a member of the selected gyms in Sleman District.

Participants were invited by the main researcher at the gym's main entrance at different times of the day and week. After being informed about the main purpose of this research, the participants were asked to complete a questionnaire, which consisted of questions on sociodemographic factors (age, sex, educational level, and occupation), tendency of ergogenic supplement consumption (consumption, routinity, start of consumption, periods, reasons, main goal, main sources, most influential advisors, places of purchasing, and cost of ergogenic supplement), comprehension about ergogenic supplement (meaning, usage, nutrient content, types, and dosage of ergogenic supplement) reality of ergogenic supplement consumption (amount, types, the use of ergogenic supplement), and impact of ergogenic supplement consumption (impact on physical performances, impact on achievementsand side effect).

Surveys were distributed to the participants and collected on the same day by the researcher. After completion, each questionnaire was verified by the researcher with the participant, to check inconsistencies in responses and therefore avoid incomplete data.

Data were analyzed using SPSS for Windows, Version 25.0. Descriptive statistics were used to summarize and explain the characteristics of the variables. In addition, chi-square test with a $p<0.05$, was conducted to assess the association between the selected factors.

\section{Result}

\section{Demographics/Characteristics of Participants}

The participants were picked by disproportionate random sampling technique, each group stratification has the same number of sample. From 258 total number of participants, 129 was male and 129 of the rest was female. They also divided into 3 age group $(<21,21-40,>40 \mathrm{y})$. Most of the participants $(72.5 \%)$ had a college degree (diploma, bachelor, master or Ph.D.). The majority of their occupations were students $42.2 \%$.

Table 1. Characteristics of Participants

\begin{tabular}{llllll}
\hline \multirow{2}{*}{ Characteristics } & \multicolumn{2}{l}{ Total Population } & \multicolumn{2}{l}{ Total Users } & P value \\
\cline { 2 - 5 } & n: 258 & $\%$ & n: 88 & $\%$ & .005 \\
\hline $\begin{array}{c}\text { Age Group (y) } \\
<21\end{array}$ & 86 & 33.3 & 22 & 25.0 & \\
$21-40$ & 86 & 33.3 & 41 & 46.6 & \\
$\quad>40$ & 86 & 33.3 & 25 & 28.4 & .000 \\
Sex & & & & & \\
$\quad$ Male & 129 & 50.0 & 76 & 86.4 & \\
$\quad$ Female & 129 & 50.0 & 12 & 13.6 & .029 \\
Education & & & & &
\end{tabular}


Primary School

Secondary School

High School

Diploma

Bachelor

Master/Ph.D

Occupation

Unemployed

Students

House Wife

Employee

Government Employee

Lecturer

Doctor

Enterpreneur

Freelance

1

70

5

176

6

16

109

4

63

3

1

1

58

3
0.4

27.1

1.9

68.2

2.4

6.2

42.2

1.5

24.4

1.2

0.4

0.4

22.5

1.2
1.1

18.3

1.1

75.0

4.5

$4 \quad 4.5$

.489

$* \mathrm{p}<0.05$

\section{Phenomenon of Ergogenic Supplement Consumption.}

The consumption of ergogenic supplements was reported by $34.1 \%$ of the participants as shown in figure 1 . This was associated by participants characteristics such as age, sex, education, and occupation as shown in table 1 . The users were generally younger and males were more interested in consuming the ergogenic supplements than females.

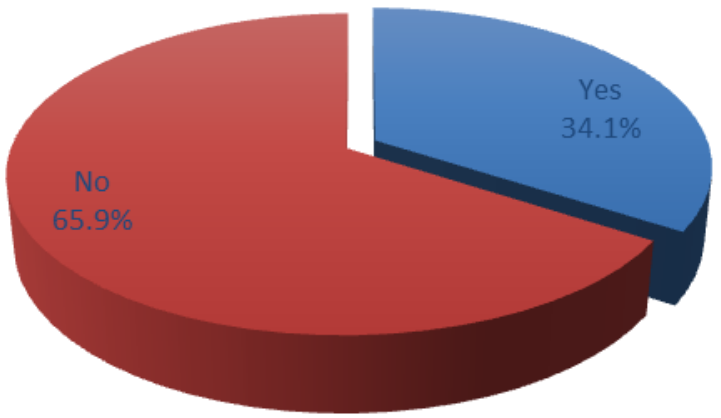

Figure 1. Ergogenic Supplements Consumption 
The phenomenon of ergogenic supplements consumptions of the users as described in table 2 below:

Table 2. The Phenomenon of Ergogenic Consumption

\begin{tabular}{|c|c|c|}
\hline & $\mathrm{n}=\mathbf{8 8}$ & $\%$ \\
\hline \multicolumn{3}{|c|}{ Consumption as routinely } \\
\hline Yes & 50 & 56.8 \\
\hline No & 38 & 43.2 \\
\hline \multicolumn{3}{|c|}{ Consumption since workout } \\
\hline Yes & 61 & 69.3 \\
\hline No & 27 & 30.7 \\
\hline \multicolumn{3}{|l|}{ Period } \\
\hline$<1 \mathrm{y}$ & 37 & 42.0 \\
\hline $1 \mathrm{y}$ & 26 & 29.5 \\
\hline $2 y$ & 9 & 10.2 \\
\hline $3 y$ & 11 & 12.5 \\
\hline$>3 y$ & 5 & 5.7 \\
\hline \multicolumn{3}{|l|}{ Reason } \\
\hline As food support & 69 & 78.4 \\
\hline Following a lifestyle & 9 & 10.2 \\
\hline Affected by ads & 1 & 1.1 \\
\hline Others & 9 & 10.2 \\
\hline \multicolumn{3}{|l|}{ Goal } \\
\hline Power and endurance & 37 & 42.0 \\
\hline Muscle development & 57 & 64.8 \\
\hline Fat loss & 20 & 22.7 \\
\hline Faster recovery & 17 & 19.3 \\
\hline Others & 2 & 2.3 \\
\hline \multicolumn{3}{|c|}{ The main source of information } \\
\hline Instructor/Trainer & 36 & 41.4 \\
\hline Friend & 39 & 44.8 \\
\hline Media & 33 & 37.9 \\
\hline Nutritionist & 9 & 10.3 \\
\hline Others & 1 & 1.1 \\
\hline
\end{tabular}




\begin{tabular}{lll}
\hline Most influential advisor & & \\
\hline Instructor/Trainer & 43 & 49.4 \\
Friend & 25 & 28.7 \\
Advertisement & 11 & 12.6 \\
Nutritionist & 6 & 6.9 \\
Others & 21 & 24.1 \\
\hline Places of purchase & & \\
\hline Pharmacies & 6 & 6.8 \\
Fitness center & 37 & 42.0 \\
Store & 41 & 46.6 \\
Internet/online shopping & 18 & 20.5 \\
Others & 2 & 2.3 \\
\hline Cost & & \\
\hline$<500.000$ & 47 & 53.4 \\
$500.000-1.000 .000$ & 39 & 44.4 \\
$>1.000 .000$ & 1 & 1.1 \\
Others/uncertain & 1 & 1.1 \\
\hline
\end{tabular}

$56.8 \%$ of users took supplements routine and regularly, and the majority of the users $(69.3 \%)$ start consuming the supplements since they work out in the fitness center.

The periods of consuming supplements were very, from $<1$ year ago -10 years ago. Most of the users $(42.0 \%)$ reported that they consumed ergogenic supplements for less than 1 year, and only $5.7 \%$ said that they have taken for longer than 3 years.

They were consuming ergogenic supplement for food support $(78.4 \%)$. Some of the users (10.2\%) consume for fitness lifestyle, and only 1 participant $(1.1 \%)$ was influenced by advertisement, while $10.2 \%$ of the rest users consume supplements for other reasons.

The main goal for ergogenic supplements consumption was to develop muscle mass (42.9\%), to increase energy and endurance $(27.8 \%)$, to lose fat $(15.0 \%)$, to recovery $(12.8 \%)$ and another goal $(1.5 \%)$.

Around $33.1 \%$ of the users got information of ergogenic supplement from their friend, and $30.5 \%$ chose instructor/coaches as the main source of ergogenic supplements information. The media only took $28 \%$, nutritionist $7.6 \%$, and the others $0.8 \%$.

The users reported taking an ergogenic supplement by a suggestion from the instructor/coaches in the gym (40.6\%), whereas nutritionist had the lowest influence (5.7\%). Friends (23.6\%), other (19.8\%), and advertisement (10.4\%).

Supplement stores (39.4\%) were the most common places for purchasing ergogenic supplements, followed by fitness center $(35.6 \%)$ and online shopping/internet (17.3\%). While pharmacies only took $5.8 \%$ and other places took $1.9 \%$.

More than half of users reported spending less than IDR 500.000/month for ergogenic supplements, and the highest cost was seen about IDR 500.000-1.000.000/month. 


\section{Comprehension of Ergogenic Supplement}

As much as 135 participants $(52.3 \%)$ reported had a high comprehension in ergogenic supplements. Only $8.5 \%$ of the participants had a low comprehension of ergogenic supplements.

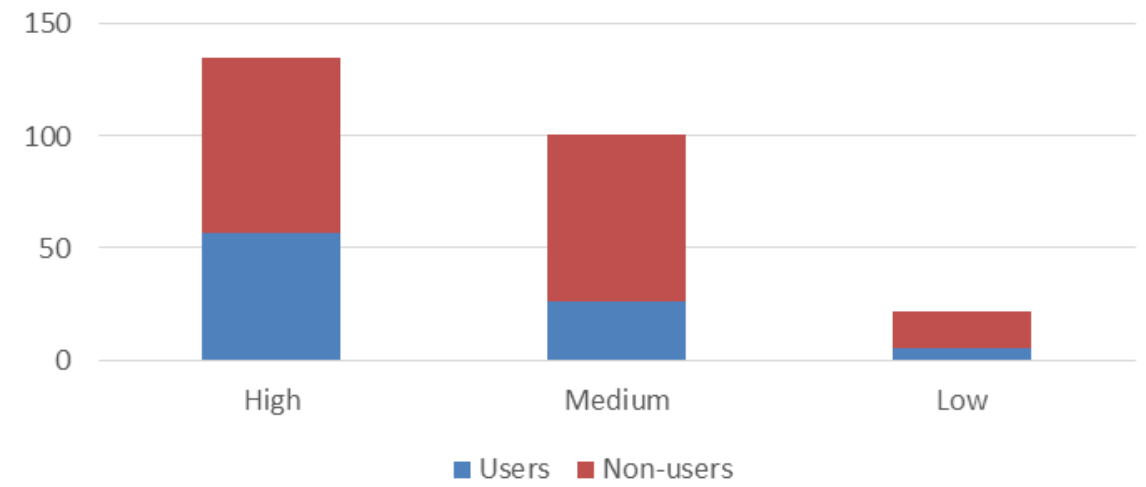

Figure 2. Participant's Comprehension of Ergogenic Supplements

\section{Reality of Ergogenic Supplement Consumption}

The consumption of 2 or more ergogenic supplement products was reported by $16.8 \%$ of the users. The most commonly consumed ergogenic supplements were whey protein $(62.1 \%)$, followed by amino $(35.6 \%)$ and BCAA $(31 \%)$. The types of ergogenic supplements that consumed by the users are listed in figure 3 below:

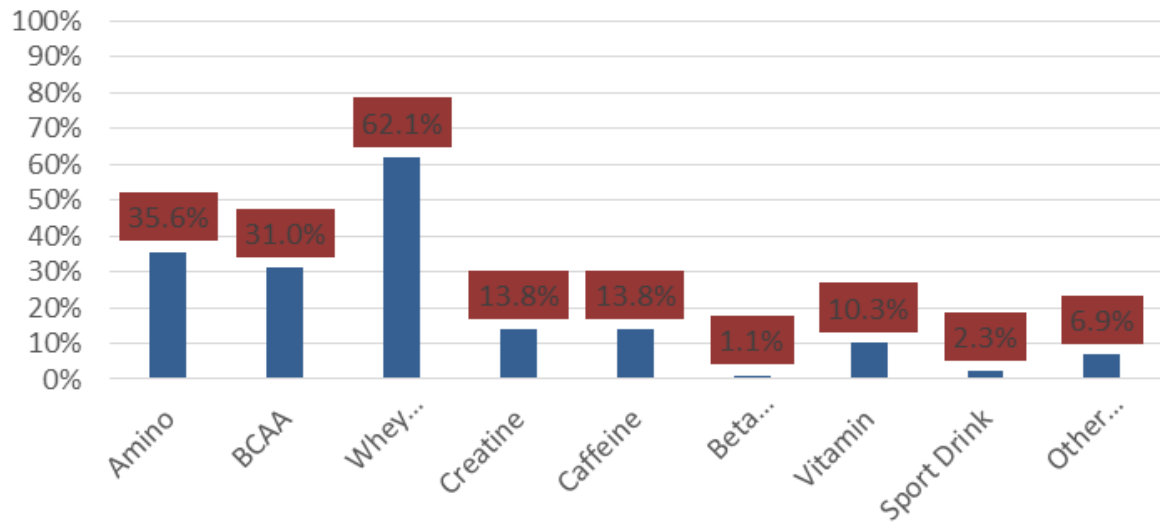

Figure 3. Type of Ergogenic Supplements Taken by Users

The users $(20.5 \%)$ reported taking ergogenic supplements by self-prescription, and $(79.5 \%)$ by a suggestion of the product (recommendation use).

More than half of the users $(67.0 \%)$ consumed ergogenic supplements without seeking any professional guidance /nutritionist. Only 33\% of the users went to the specialist (physicians, doctors, nutritionists).

Although, most of the users (83\%) seeking further information about the ergogenic supplement that consumed. 
Only $3.4 \%$ of the users mentioned the used of illegal substances. They had used a combination of ergogenic supplements and illegal substances (steroids). The use of this combination was seen among male users.

\section{Impact of Ergogenic Supplement Consumption}

About $33.7 \%$ of the participants believed that consuming ergogenic supplements have an impact on exercise performance. $85.2 \%$ of users said their physical performance increased. $73.9 \%$ felt body composition balanced, and $80.7 \%$ time in recovery became faster.

Almost half of the users $(42.0 \%)$ reported having obtained the desired response with the consumption of ergogenic supplements.

The majority $(72.7 \%)$ said the consumption of ergogenic supplements caused no side effects. However, a little number of the users reported some problems such as hormonal reaction (18.2\%), addiction $(8.0 \%)$, or some impact on health $(10.2 \%)$.

\section{Discussion}

Previous studies have shown various rates of supplement use among people who exercise in the fitness center. Prevalence of supplement consumption including ergogenic supplements was reported as high as $88.6 \%$. This indicates that there is a high prevalence of ergogenic supplements consumption and tendency to consume ergogenic supplements that have increased considerably over the last few years.

In this study, it was found that as many as $34.1 \%$ of participants took ergogenic supplements. This number is more or less close to the previous study conducted by Goston and Correia (36.8\%) and study by El Khoury and Antoine-Jeville (36.3\%).In other studies, it was known that the level of supplement use was different and varied among people who exercised at the fitness center. The results of different studies may be explained because of the different types of fitness centers and respondents involved in them.

In the current study, ergogenic supplements consumption was significantly associated with age group, sex, and education. Ergogenic supplements are more likely to be consumed by men and younger age groups. This is in accordance with the research conducted by Goston and Correia that supplement use was reported to be higher among male exercisers. In addition, in this study, it was also found that there was no significant association between occupation and the consumption of ergogenic supplements. More than half of the users took ergogenic supplements as a routine. The routine of consuming supplements is usually because respondents are accustomed to taking supplements during exercise while at the fitness center. The majority also took the ergogenic supplements since they went to the fitness center. They get information about the supplements when visiting the fitness center. Then the respondents began to recognize and consume ergogenic supplement products offered at the fitness center.

Almost half of the users (42\%) started taking ergogenic supplements less than 1 year ago. The period of use of these supplements indicates that they are consumers who are trying to consume supplements. However, there are various periods of supplement use. As many as $10.2 \%$ of respondents consumed supplements since 2 years ago. Then $12.5 \%$ consumed since 3 years ago and only about $5.7 \%$ of respondents consumed supplements more than 3 years ago. The length of consumption of supplements by members of the fitness center is usually in accordance with the length of time the member exercises in the fitness center.

The general reason for users is as food support, which is $78.4 \%$. This is in accordance with the function of supplements, namely as additional nutritional intake / main food companion. It was also found as many as $10.2 \%$ of respondents who consumed supplements to follow a lifestyle in the fitness center. Only $1.1 \%$ of respondents consumed on the grounds of being affected by advertising and $10.2 \%$ had other reasons for taking ergogenic supplements.

More than half of supplement users, $64.8 \%$, stated that the goal of taking ergogenic supplements is for muscle development. In sports fitness, bodybuilding is indeed more in demand by members of the 
fitness center who practice. Then $42 \%$ of respondents who consumed supplements aimed at energy and endurance. $22.7 \%$ stated that fat burning and $19.3 \%$ had the goal of fast recovery. About $2.3 \%$ of respondents take supplements for other purposes.

The main source of information for users is friends, with a percentage of $44.8 \%$, followed by instructors/trainers with a percentage of $41.4 \%$. The source of information originating from the media received a percentage of $37.9 \%$, then nutritionists by $10.3 \%$ and others, namely $1.1 \%$. Based on these results, it can be explained that information originating from friends and instructors/trainers is information that is more trusted by the majority of respondents than information obtained from other sources.

As many as $49.4 \%$ of users stated that the instructor/trainer in the fitness center as a source of influence for consuming ergogenic supplements. Then there were $28.7 \%$ who stated friends, $12.6 \%$ who stated advertisements and $6.9 \%$ who stated that nutritionists were the influencing source for taking ergogenic supplements. There were also $24.1 \%$ of respondents who stated that other sources affected the consumption of ergogenic supplements. Based on these percentages, the instructor/trainer is the most influential source of respondents for taking ergogenic supplements. This may be explained that the instructor/trainer has had many experiences related to the consumption of ergogenic supplements. In addition, the instructor/trainer may prove the benefits and get results from consuming supplements, so the instructor/trainer can influence the respondents to consume the ergogenic supplements.

The most preferred place for users to buy ergogenic supplements is the supplement store, which is $46.6 \%$. In addition, $42 \%$ of respondents stated that the place to buy supplements was at the fitness center. In this case, respondents seem to prefer to shop directly compared to shopping online through the internet which only gets a percentage of around $20.5 \%$. But there are also a small number of respondents, namely $6.8 \%$ choosing to buy at a pharmacy and $2.3 \%$ choosing to buy elsewhere.

More than half of the respondents, as many as $53.4 \%$ issued a budget for purchasing supplements less than IDR 500,000.00. Then it was followed by $44.4 \%$ of respondents who spent a budget between Rp. 500,000 - Rp. 1,000,000.00. The budget spent by fitness center members for ergogenic supplements is mostly in the range of less than Rp. 500,000.00. The amount of budget spent on the purchase of ergogenic supplements is considered to be a little expensive for some respondents, considering that the majority of respondents work as students. Although there are also respondents who spend more than Rp $1,000,000.00$, which is as much as $1.1 \%$. In addition, $1.1 \%$ of respondents stated that the budget spent on consuming supplements was uncertain. This can be explained that the level of the economy for each respondent is different from one another, so the budget level that is most commonly found in the lowest budget in this study.

From the number of respondents who consumed ergogenic supplements showed that more respondents had knowledge of high ergogenic supplements which amounted to $64.8 \%$ compared to respondents who consumed supplements with moderate and low knowledge. The high level of knowledge about ergogenic supplements is not necessarily a guarantee that someone makes the decision to consume them. Someone with a high level of knowledge will have an awareness of better nutrition, especially in choosing the right type of food to consume to meet their caloric needs, so that they would prefer to consume a balanced diet compared to taking supplements. In addition, if the person is taking ergogenic supplements, it is expected to be able to use wisely and be able to take the benefits needed without causing undesirable negative impacts.

The most common ergogenic supplements consumed by members of fitness centers in Sleman Regency are whey protein $(62.1 \%)$, amino (35.6\%), and BCAA (31.0\%). These three supplement products have similarities which contain protein. Protein-containing supplements have been theorized to have an ergogenic effect (Lawrence \& Kirby, 2002). According to Applegate and Grivetti (1997) and Ciocca (2005), protein is the most widely used source of ergogenic nutrition in recent times. Protein is needed for growth, development, muscle formation, a formation of red blood cells, defense of the body against diseases, enzymes, and hormones, and the synthesis of other body tissues.

The majority of users, namely as many as $79.5 \%$ consume the ergogenic supplements according to the rules of use. However, there are still respondents who consume not according to the rules of use, which is equal to $20.5 \%$. The rules used are usually printed on the supplement product packaging 
consumed. The consumption of ergogenic supplements that are in accordance with the rules of use is very important, where supplement products certainly already have their own dose to function optimally.

Many members of the fitness center who consume ergogenic supplements are not consulted by nutritionists, as much as $67 \%$. Only $33 \%$ of respondents who consumed ergogenic supplements were accompanied by supervision by a nutritionist. This illustrates the lack of awareness of respondents to use supplements properly and safe for health.

Although supplement consumption was not accompanied by consultation with nutritionists, in fact, $83 \%$ of respondents sought further information about ergogenic supplement products consumed. In this case, the initiative of respondents using ergogenic supplements is quite high because there is still a curiosity about the supplement products consumed.

Almost all users, namely $98.9 \%$ consumed products that were legal and safe for consumption. The products consumed by respondents are products whose sales circulation is still free in Indonesia. These products can be found at supplement stores, fitness centers, pharmacies, and internet shopping online.

In this study, it was found that respondents who consumed ergogenic supplements contained steroids and other illegal substances, although in relatively small amounts, namely $3.4 \%$. Respondents who consume steroids and illegal substances usually require large ergogenic effects with the aim of obtaining results quickly. Changes in the body after taking this type of supplement are far more significant compared to ordinary ergogenic supplements sold on the market. However, the long-term side effects produced after consuming supplements containing steroids and illegal substances are also more dangerous and tend to be life-threatening. Therefore, ergogenic supplements containing steroids and illegal substances are very limited in circulation and are not sold freely.

98.9\% of users who consumed ergogenic supplements showed that almost all felt there was an impact after taking ergogenic supplements. A total of $85.2 \%$ of respondents felt the impact of an increase in physical performance, $73.9 \%$ of respondents said body composition becomes more balanced, and $80.7 \%$ of respondents said the recovery was faster. Based on this description, ergogenic supplements have been shown to have the ability to increase the body's performance capacity.

As many as $55.7 \%$ of respondents who consumed supplements had increased performance. This can be explained that for some respondents, the consumption of ergogenic supplements can help them to achieve achievements in the field of sports related to muscle strength and bodybuilding. Usually, they are amateur athletes who are in competition. However, a total of $58.0 \%$ of respondents stated that the results of the achievement were not in line with the expectations desired by supplement users. This is because of the hopes of those who always want to win in every competition.

The majority of respondents, namely as many as $72.7 \%$ did not feel any side effects in taking ergogenic supplements. However, a small number of respondents encountered several cases such as $8 \%$ experiencing dependence, $10.2 \%$ experiencing health problems and $18.2 \%$ experiencing hormonal changes even in small amounts.

\section{Conclusion}

In conclusion, the consumption of ergogenic supplements in members of fitness centers in Sleman Regency is low. As many as $34.1 \%$ of members of the fitness center in Sleman Regency consume ergogenic supplements. The consumption of ergogenic supplements also has a relationship with several variables, namely age $(p=0.005)$, gender $(p=0.000)$ and education $(p=0.029)$. However, there is no relationship between consumption of ergogenic supplements and occupational variables $(\mathrm{p}=0.489)$.

Knowledge of ergogenic supplements in members of fitness centers in Sleman district is high. As many as $52.3 \%$ of members of the fitness center in Sleman Regency have a high level of understanding of ergogenic supplements. 
The reality of the consumption of ergogenic supplements in members of the fitness center in Sleman Regency is low. As many as $27.9 \%$ of members of the fitness center in Sleman Regency generally only consume 1-2 kinds of ergogenic supplements.

There is an impact felt by members of the fitness center in Sleman Regency who consume ergogenic supplements. As many as 33.7\% of members of the fitness center in Sleman Regency feel a change after consuming ergogenic supplements.

\section{Conflict of Interest}

The authors certify that have NO affiliations and conflict of interest with any organization or entity with any financial interest or nonfinancial interest in the subject matter or material discussed in this manuscript.

\section{Acknowledgements}

The author realizes that the preparation of this article can't be separated from the help of various parties, on this occasion the author expressed her gratitude to:

1. Prof. Dr. Sugiyanto as the first supervisor who has taken the time to guide with patience and thoroughness and provide direction in the completion of the research.

2. Dr. NoerRachma, dr. Sp. KFR. as the second supervisor who patiently and thoroughly continued to guide the author in the completion of the research.

3. Principles of the fitness center/gym who help a lot and giving the research permission

4. Study participants who willingly spent their time to help the research

\section{References}

Apostu, Mihaela. (2013). The Effect of Ergogenic Substances over Sports Performance. Procedia-Social and Behavioral Sciences, 117(2014), 329-334.

Attlee, Amita.,Haider, Amina., Hassan, Asma., Alzamil, Noura., Hashim, Mona., and Shaker Obaid, Reyad. (2017). Dietary Supplement Intake and Associated Factors Among Gym Users in a University Community. Journal of Dietary Supplements, 15(1), 88-97.

Braun, H. et al. (2009). Dietary Supplement Use Among Elite Young German Athletes. International Journal of Sport Nutrition and Exercise Metabolism, 19(1), 97-109.

Burke, L., Cort, M., Cox, G., Crawford, R., Desbrow, B., Farthing, L.,Warnes, O. (2006). Supplements and sports foods. In Clinical sports nutrition (3 ed., Vol. 3, pp. 485-579). [16] Sydney, Australia: McGraw-Hill Education.

Delimaris, Ioannis. (2017). The Role of Legally Available "Ergogenic" Nutritional Supplements in Exercise Performance: A Biochemical and Physiological Approach. Anatomy Physiology\& Biochemistry International Journal,2(1),555576. doi: 10.19080/APBIJ.2017.02.555576.

El Khoury D, Antoine-Jonville S.(2012). Intake of Nutritional Supplements among People Exercising in Gyms in Beirut City. J NutrMetab, 2012:703490. doi: 10.1155/2012/703490.

Erdman KA, Fung TS, Reimer RA. (2006). Influence of performance level on dietary supplementation in elite Canadian athletes. Med Sci Sports Exerc, 38(2), 349-56. 
Froiland, Kathryn. et al. (2004). Nutritional Supplement Use Among College Athletes and Their Sources of Information. International Journal of Sport Nutrition and Exercise Metabolism, 14(1), 104-20.

Goston, J. L., \&Correia, M. I. (2010). Intake of nutritional supplements among people exercising in gyms and influencing factors. Nutrition, 26(6), 604-611.

Huang SH, Johnson K, Pipe AL. (2006). The use of dietary supplements and medications by Canadian athletes at the Atlanta and Sydney Olympic Games. Clin J Sport Med, 16(1), $27-33$.

Maughan, R. J., King, D. S., \& Lea, T. (2004). Dietary supplements. Journal of Sports Sciences, 22(1), 95-113.

McDowall, Jill Anne. (2007). Supplement Use by Young Athletes. Journal of Sport Science and Medicine, 6(3), 337-342.

Mckinley.illinois.edu. (2011). McKinley Health Center-Ergogenic Aids: Nutritional Supplement for Athletes. University of Illinois.

Morrison LJ, Gizis F, Shorter B. (2004). Prevalent use of dietary supplements among people who exercise at a commercial gym. Int J Sport NutrExercMetab, 14(4), 481-92.

M.S. Howard et al. (2018). Perspectives of athletes and pharmacists on pharmacist-provided sports supplement counseling: An exploratory study. Journal of the American PharmacistsAssociation,58(4),S30-S36. doi: https://doi.org/10.1016/j.japh.2018.05.003.

Office of Dietary Supplements of the National Institutes of Health. (2017). Fact Sheet - Dietary Supplements for Exercise and Athletic Performance. Viewed 13 April 2019. https://ods.od.nih.gov/factsheets/ExerciseAndAthleticPerformance-\ HealthProfessional/\#en2.

Palmer ME, Haller C, McKinney PE, et.al. (2003). Adverse events associated with dietary supplements: an observational study. Lancet, 361(9352), 101-106.

Saeedi, Pouya. (2012). Nutritional Supplement Use Among Fitness Club Participants in Tehran, Iran. Appetite, 60(2013), 20-26.

Sobal J, Marquart LF. (1994). Vitamin/mineral supplement use among high school athletes. Adolescence, 29(116), 835-43.

Striegel H, Siomn P, Wurster C, Niess AM, Ulrich R. (2006). The use of nutritional supplements among master athletes. Int J Sports Med, 27(3), 236-41.

Wiens, K. et al. (2014). Dietary Supplement Usage, Motivation, and Education in Young Canadian Athletes. International Journal of Sport Nutrition \& Exercise Metabolism, 24(6), 613-622.

\section{Copyrights}

Copyright for this article is retained by the author(s), with first publication rights granted to the journal. This is an open-access article distributed under the terms and conditions of the Creative Commons Attribution license (http://creativecommons.org/licenses/by/4.0/). 